\title{
Analysis of the State and Development Prospects of the Irrigation Equipment Fleet in the Russian Federation
}

\author{
Gennadii Olgarenko*, and Sergei Turapin
}

Federal State Budgetary Scientific Institution All-Russian Research Institute of Irrigation and Agricultural Water Supply Systems «Raduga», Kolomna urban district, Raduzhny, Russia

\begin{abstract}
The article presents the results of monitoring the availability and state of production of irrigation machinery and equipment in Russia. Based on the information and analytical studies carried out, data on the structure of the irrigation equipment fleet are presented, taking into account the availability and supplies of Russian and imported equipment. A complex of engineering, technical, organizational, and managerial measures has been developed, aimed at providing agricultural producers with domestic irrigation machinery, corresponding to the modern scientific and technical level of technology development in the world. A relevant issue is not only the conduct of experimental design and technological work on the development of a new generation of sprinkling equipment, which has the author's priority of the Russian Federation but also a comprehensive State policy is needed, which creates opportunities for Russian machine-building enterprises to organize and develop serial production, will reduce the dependence of the melioration industry on imported equipment, which is consistent with the goals of the Food Security Doctrine and the Import Substitution Strategy in the Russian Federation. AIC.
\end{abstract}

\section{Introduction}

The main zones of agricultural production in the Russian Federation are located in difficult natural and climatic conditions: a shortage of natural moisture supply is observed on more than $70 \%$ of arable land. Sustainable production of agricultural products in the arid climatic zone of the Russian Federation can be ensured only through the development of irrigation of agricultural lands $[1,2]$.

The efficiency of using water, soil, climatic, material, technical, and energy resources, the ecological state of the environment, largely depends on the quality of technologies and irrigation techniques, which determines the quality of water distribution and regulation of the soil water regime, and therefore the yield of crops and the amount of unproductive losses of irrigation water.

An important risk factor for the further development of irrigated areas is the insufficient number of new Russian research and development projects on sprinkler equipment,

\footnotetext{
* Corresponding author: olgarenko@ mail.ru
} 
introduced into production, in the presence of a significant share of foreign irrigation equipment. Give to foreign companies complete control of the solution of issues of technical assistance of the Subprogram for the development of the amelioration complex of Russia (hereinafter - the "Melioration Program") operating under the State Program for the Development of Agriculture, Regulation of Raw Materials and Food Markets, approved by Decree of the Government of the Russian Federation No. 717 dated June 14, 2021, as amended by the Government Resolution of the Russian Federation No. 415 dated March 18, 2021 (hereinafter - the "State Program of the Agroindustrial Complex"), in terms of construction, reconstruction and technical re-equipment of hydro-reclamation systems, since it contradicts the requirements of food and technological security of Russia [3].

Therefore, it is very important not only to develop design documentation for a new generation of sprinkler equipment, which has the author's priority of the Russian Federation but also to ensure serial production necessary for the development of irrigated agriculture, irrigation technology, and irrigation equipment development, corresponding to the world level of scientific and technological development $[4,5]$.

To implement the import substitution program in the field of hydro reclamation, a State policy is required that creates opportunities for Russian machine-building enterprises to organize and develop serial production, which corresponds to the objectives of the State Program for the AIC Development and will reduce the dependence of the land reclamation industry on imported equipment.

\section{Purpose}

To analyze the engineering and technical level and technical and operational parameters of irrigation equipment involved in agricultural production. To substantiate the need and scientific and technological capabilities of Russian research organizations and machinebuilding enterprises to ensure the modernization of the machine-technological base of agricultural producers working on irrigated lands, on the basis of organizing the production of domestic irrigation equipment with a material and technical base, a complete set of technical documentation and author's rights for the organization of serial production of irrigation equipment.

\section{Research methodology}

FSBSI All-Russian Research Institute Raduga conducts research on monitoring the actual state, assessing the technical level and operation of hydro-reclamation systems, solving issues of development, production, implementation, and operation of new irrigation equipment. $[6,7,8]$.

Scientific research used the following as a scientific and methodological base: promising developments of research and production organizations, works of foreign and domestic scientists in the field of technologies and technical means of irrigation; the results of scientific and technical activities in the field of technologies and equipment for sprinkling irrigation, obtained under the guidance and direct participation of the authors during the implementation of experimental design work $[3,4]$.

FSBSI All-Russian Research Institute Raduga monitored the supply and availability of irrigation equipment in agricultural production and the state of domestic production for various types of technical irrigation equipment. For conducting monitoring, special forms of statistical observations on irrigation equipment were developed, based on the previously existing 2-mech form, including all types of irrigation equipment at the modern level. The research studied volumes of products, production potential, the presence of service centers in 
the regions of Russia, the completeness of the development of technical documentation for the production of equipment, the availability of patented technical solutions, certification, test results, as well as the supply of irrigation equipment from foreign countries according to the Customs Committee of the Russian Federation and analysis of the results of the implementation of the Reclamation Program in 2014 - 2020.

\section{Research results}

The reclamation fund of the Russian Federation amounted to 9.46 million hectares at the beginning of 2020, [6.7] with the following structure of reclaimed land:

- out of 4.68 million hectares of irrigated land, 3.89 million hectares were actually used in agricultural production, and irrigation was carried out due to the supply of water by state reclamation systems on an area of 1.41 million hectares and due to the initiative actions of agricultural producers for irrigation of local runoff waters of about 0.50 million hectares;

The state reclamation infrastructure ensures the operation of hydro-reclamation systems with an area of reclaimed land of 3.8 million hectares, of which 2.9 million hectares on irrigation systems. State HMS supplies water through the main and inter-farm network for irrigation on the on-farm irrigation systems, with an area of about 1.41 million hectares, with a volume of water intake for irrigation of about $7.0 \mathrm{~km} 3$.

The structure of irrigated areas irrigated due to water supply by the State Hydroreclamation systems, total $-1,412.0$ thousand hectares $(100 \%)$, including: grain crops -233.0 thousand hectares $(16.5 \%)$; rice - 185.0 thousand hectares $(13.0 \%)$; vegetables - 227.0 thousand hectares $(16.5 \%)$; fodder crops - 487.0 thousand hectares $(34.5 \%)$ : other crops 278.0 thousand hectares $(19.50 \%)$.

The structure of irrigated areas, according to irrigation equipment, is as follows: sprinkler equipment, 8,367 units in total provide irrigation on an area of 540.0 thousand hectares, including wide-coverage sprinklers - 6,592 units provide irrigation of an area of at least 400.0 thousand hectares; hose barrel sprinklers in the amount of 1,088 units provide irrigation of an area of at least 20.0 thousand hectares; stationary sprinkler systems with 194 units provide irrigation up to 10.0 thousand hectares; sprinklers DDA-100, DDN-70:100, with 853 units, provide irrigation on an area of 80.0 thousand hectares; sprinklers, based on the collapsible pipelines, with 763 units, provide irrigation of about 40.0 thousand hectares; micro-irrigation systems (drip watering), with 3,198 sets that provide irrigation up to 100.0 thousand hectares; total surface irrigation on an area of 770.0 thousand hectares, including rice irrigation systems of about 185.0 thousand hectares. [8.9]

Foreign manufacturing enterprises from the USA, UAE, Turkey, Austria, Germany, and Italy are actively operating and promoting their irrigation equipment on the Russian market, including Valley (USA), Zimmatik (USA), Reinke (USA), TL (USA), RKD (Spain), Western (UAE), Lindsay (Turkey), Bauer (Austria), Beinlich (Germany), Ocmis, RM, Nettuno, Idrofoglia, Irtec, Irrimec (all - Italy).

According to an expert assessment, about 1,690 wide-coverage sprinklers and 550 hose barrel sprinklers were imported in total in 2016-2020, which on average per year is at least 400 wide-coverage electrified sprinklers (WCES) and about 100 hose barrel sprinklers (HBS).

According to the Russian customs, the following irrigation equipment was imported into the territory of the Russian Federation:

Hose barrel sprinklers, 550 units. Main suppliers: Italy - 98.0\% including: IRRIMEC $25.6 \%$; OCMIS - 16.7\%; RM - 22.2\%; NETTUNO - 13.5\%; IRTEC - $11.5 \%$.

The total cost of imports is $\$ 9.87$ million, while the average cost of the HBS is $\$ 18.50$ thousand (the maximum price per unit is $\$ 23.80$ thousand, the minimum is $\$ 10.80$ thousand). 
A total of 1,690 wide-coverage sprinklers (WCES) were delivered to Russia, excluding spare parts and equipment. Major foreign suppliers: Valley, Lindcey, TL, Reinke, Bayer.

The cost of import supplies is about $\$ 120.60$ million, with an average cost of one WCES about $\$ 95.0$ thousand (the maximum price for one WCES is up to $\$ 110.0$ thousand, the minimum price is $\$ 75.0$ thousand.

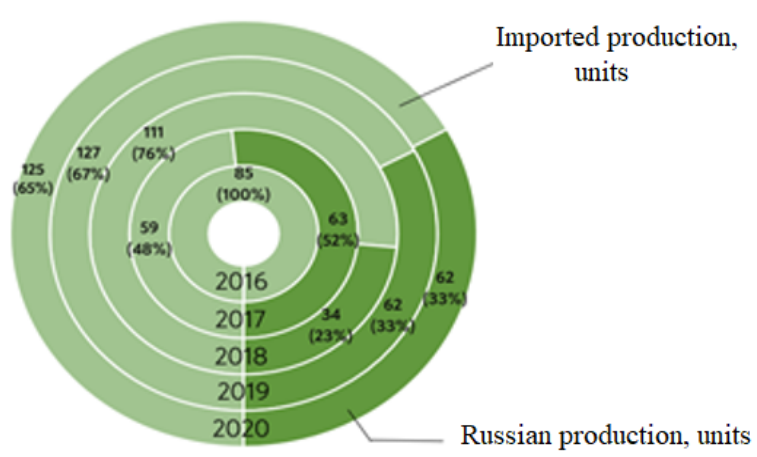

Hose Drum Sprinklers

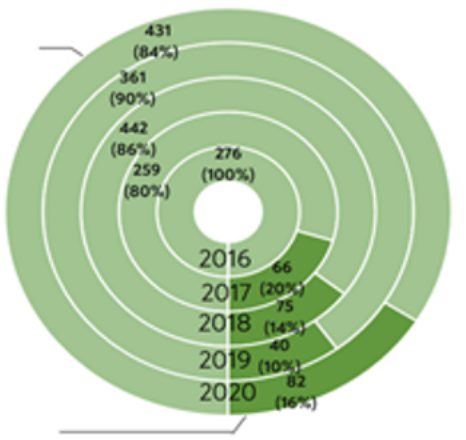

Large-coverage sprinklers

* Serial production of hose reel and wide-grip sprinklers in the Russian Federation has been launched since 2017

* Data on the supply of imported sprinkler equipment are determined from the databases of the customs of the Russian Federation. Data on deliveries of Russian sprinkler equipment are presented by domestic manufacturers

Fig. 1. Supplies of irrigation equipment in the Russian Federation.

Mobile sprinkler systems with medium-range sprinklers. A total of 110 kits were supplied for irrigation of 7.0 thousand hectares. Main suppliers: Rein Berd, Raesa, Bayer. The total volume of imports is $\$ 5.0$ million. The average cost of a mobile kit is about $\$ 60,0$ thousand, with a maximum price of one kit up to $\$ 65,0$ thousand, and a minimum price of $\$ 40,0$ thousand.

A total of 300 sets of drip irrigation systems (DIS) were delivered to Russia for the amount of about $\$ 32.0$ million.

Main suppliers: Netafim ltd (Israel) - 60\%; Seo won co., Ltd (South Korea) -10.0\%; "Hekimoglu plastik ve kalip sanayi - recep gumus" (Turkey) - 10\% Metzerplas ltd (Israel) $10.0 \%$ Micro mist irrigation products co., Ltd (China) - 5\%, other - about 10\%.

Serial production of domestic sprinkler equipment resumed in 2015. The first serial samples were manufactured, passed State tests, and put into mass production in 2016. Produced and supplied to agricultural producers of sprinkler equipment: wide-coverage sprinkler machines (WCES), domestic for 2016-2020 amounted to 250 units, or on average about 50 wide-coverage sprinkler machines per year:

"Kazan Irrigation Equipment Plant" - production started in 2016, by the beginning of 2020 produced in total - 91 WCS, including 2017 - 34 WCS, 2018 - 37 WCS: 2019 -20 WCS.

OOO BSG - the production of wide-coverage MDM Fregat was started in 2016, a total of 60 MDM Fregat were produced by 2020, including 2016 - 20 MDM, 2017 - 4 MDM, 2018 - 20 MDM, 2019 - 20 MDM Fregat. Modernization of outdated models of DM Fregat (DM), available from agricultural producers, was carried out: 2017 - 4 DM, 2018 - 9 DM.

The production of wide-coverage sprinkler machines with an electric drive of the WCES Kuban type was launched in 2019; 25 Kuban WCES were produced. 
The production of hose barrel sprinklers (HBS) for 2016-2019, amounted in total to 174 units, or on average about 40 HBS per year.

OOO "ZDM Sprinkler Plant" started production in 2015, in total for 2016-2019, 120 Harvest HBS were produced, including 2016 - 15 HBS, 2017 - 21 HBS, 2018 - 22 HBS, 2019 -62 BDM.

OAO "Promtraktor-Wagon", Tractor Plants Concern - produced Niagara HBS for 2016 2017 - 42 HBS, 2018 - 12 HBS.

Production of fast prefabricated pipes for irrigation.

OOO "POLYPLASTIC Group" (Omsk) manufactures plastic pipelines and couplings, mobile irrigation kits from fast prefabricated pipelines for irrigation of areas of 5, 10, 15, 25, and 50 hectares. There are design and technical documentation, as well as technical documentation of the production cycle. Serial production was organized. The current production capacity is 500 mobile irrigation kits per year. Localization of production in the Russian Federation up to $80 \%$ (imports: couplings and fittings, sprinklers) Groups of regional dealers and service centers for equipment in the regions of the Russian Federation have been formed.

Drip irrigation systems.

OAO "Tuboflex" (Uglich): Drip irrigation systems, components: drip tape with a production volume of up to 200.0 million linear meters, per year; start-connectors for drip tape - production volume up to 500.0 thousand pieces per year; repair fittings for drip tape production volume up to 500.0 thousand pieces per year; pressure and inlet hoses for reclamation equipment - production volume up to 5.0 million linear meters per year. Serial production - drip tape deliveries in 2016-2018 to the regions of Russia over 300.0 million linear meters (about $20 \%$ of the market).

OOO "INTECO" (Rostov Region, Novoshakhtinsk). Drip irrigation systems, accessories: drip tape with a production volume of up to 420.0 million linear meters; components: start connectors, fittings, mini valves, rubber gaskets for drip irrigation systems - 4.0 million pieces for each type of equipment per year; connecting fittings for LayFlat more than 300.0 thousand units. Serial production, the volume of manufactured products amounted to 280.0 million linear meters.

ZAO "New Age of Agrotechnology" (Lipetsk Region, Chaplygin). Drip irrigation systems, accessories: drip tape with a production volume of up to 300.0 million linear meters per year. Technical and technological documentation is available in the full volume necessary for serial production. Own production base. Serial production, the volume of manufactured products amounted to 280.0 million linear meters.

The main nomenclature of technical means and equipment for irrigation of land plots of agricultural producers using irrigated land, offered on the Russian market by Russian and foreign manufacturers:

- pneumatic-tired wide-coverage sprinklers of circular and frontal action with an electric drive, operating in automatic mode from a closed network, the area of irrigation per season is from $10-50$ to 200 hectares;

- hose barrel sprinklers with medium-range devices or cantilever cars with low-pressure devices, service area per season from 3 to 30 hectares;

- portable quick-assembly sprinkler pipelines made of aluminum or plastic, service area per season up to 50 hectares;

- a wide range of equipment, including sprinklers operating at a pressure of 0.3 to $0.5 \mathrm{MPa}$, low-pressure sprinkler nozzles operating at a pressure of 0.1-0.2 $\mathrm{MPa}$, shut-off and control hydraulic fittings, pressure and flow regulators, booster pumps, and power pumping equipment, special devices for applying fertilizers with irrigation water, computer systems and technical means for automatic irrigation control; 
- for drip irrigation systems: drip tubes and tapes with pressure compensated and uncompensated drippers, connecting fittings kits, flexible Layflat (LFT) pipelines with a diameter of 2-4" with a working pressure of 4-9 atmospheres, control and shut-off valves, fine and coarse filters, of various capacities, fertilizer application units, air release valves, control, and automation systems for the irrigation process, as well as spare parts and accessories for equipment installation;

- for micro-sprinkling systems: a wide range of micro-sprinklers operating at pressures from 0.15 to $0.35 \mathrm{MPa}$, low-pressure sprinklers operating at a pressure of 0.1-0.2 $\mathrm{MPa}$, racks and nozzle holders, shut-off and regulating fittings, pressure regulators and booster pumps, pumping and power equipment, special equipment for applying fertilizers with irrigation water, computerized irrigation control systems.

All irrigation equipment is focused on operation from a closed irrigation network, automated operation, multipurpose use, the use of computer monitoring and control systems, a wide range of modifications and options, maximum accounting of specific conditions of use. [10]

\section{Result and discussion}

An analysis of the commissioning of reclaimed land and the supply of sprinklers in previous years (2016-2019) shows that the market was mainly closed due to the supply of imported equipment. According to an expert assessment, about 1,690 wide-coverage sprinklers and 550 hose barrel sprinklers were imported in total in 2017-2020, which on average per year is: at least 350 wide-coverage electrified sprinklers (WCES) and more than 100 hose barrel sprinklers (HBS). This equals up to 5 billion rubles per year. Since only imported equipment is purchased everywhere, significant amounts of financial resources are withdrawn abroad, from the country's economy every year, including tax payments, as well as the possibility of creating jobs in the foreign economy and contributing to the social and economic development of foreign countries.

In fact, at the beginning of 2020, over the past three years, in the context of average annual supplies, Russian manufacturers increased their participation from $0 \%$ to $15 \%$ for widecoverage sprinklers, and for hose barrel sprinklers from $0 \%$ to $3 \%$ of the supplies volume of foreign equipment.

The cost of equipment from foreign manufacturers, with an expert assessment of information resources and offers from foreign manufacturers of these dealerships, is: widecoverage circular sprinklers - $\$ 75.0$ - 100 thousand (basic machine with a service area of up to 70 hectares per season); wide-coverage frontal sprinklers \$90.0-120.0 thousand (basic machine with a service area of up to 70 hectares per season); hose barrel sprinklers with a hydraulic drive $€ 35.0-42.0$ thousand (basic machine with a service area of up to 30 hectares per season), drip irrigation systems - \$20.0 - 25.0 thousand (basic module with a service area of up to 10 hectares); stationary sprinkling systems - \$25.0-30.0 thousand (basic module for servicing an area up to 10 hectares); micro-sprinkling systems \$30.0-40.0 thousand (module - 10 hectares), with practically identical technical and operational indicators of equipment from various foreign manufacturers.

An analysis of the pricing policy of domestic and foreign manufacturers shows that the difference between the cost of domestic and imported irrigation equipment is 400,000 $1,600,000$ rubles, and the difference in the amount of subsidies is from 250,000 rubles in the case of hose barrel machines, and from 800,000 rubles when buying wide-coverage sprinklers. It is important to note that when purchasing imported equipment, not only the farmer or agricultural enterprise overpays, but also the Russian budget when paying subsidies. It turns out that subsidies for the purchase of imported machines generate tax 
payments in countries where a foreign manufacturer is located (USA, Austria, Spain, Italy, Germany, Turkey, UAE).

Analysis of the irrigation equipment market shows that the share of imported sprinkler equipment is growing because large-scale serial production of Russian sprinkler equipment has not been established in recent years mainly due to the lack of high-quality design and technological documentation. During all the years of the implementation of the Land Reclamation Development Program, the irrigated land was commissioned mainly due to the supply of imported irrigation equipment, which, on average, is more than $95 \%$ of the total amount of technical equipment on the commissioning irrigated land.

The main problems hindering the development and widespread introduction of domestic irrigation equipment:

- lack of specialized sale centers (pre-sale preparation) and service maintenance - production base;

- lack of floating funds from small and medium agricultural producers for the development of design specifications and estimates and the purchase of irrigation equipment;

- orientation of large agricultural producers to imported irrigation equipment and technologies;

- Problems of training engineers - hydraulic engineers, mid-level technical specialists, and workers for production, installation, operation of irrigation equipment.

Important negative factors hindering the development of domestic production are unfair competition of foreign manufacturers: dumping offers from foreign manufacturers, including those made in China under the brand name of well-known brands; lack of priority for the Russian manufacturer in the allocation of subsidies for the purchase of irrigation equipment, within the framework of the Land Reclamation Development Program; the negative reputation of domestic irrigation equipment, due to several manufacturers who supplied irrigation machines of poor quality, without subsequent service and those who left the market; lack of experience in research and production activities in the development and organization of production of irrigation equipment, promotion of irrigation equipment on the market.

The tasks of creating and developing domestic production are not solved (not closed) only in the field of research and development, but should be solved systematically with the implementation of a single complex of organizational, production, institutional, personnel problems and require appropriate scientific, methodological, regulatory and technical support, development of material, technical and resource base of scientific, educational and operational organizations of machine-building enterprises. [11]

At the moment, Russian manufacturers are ready and able to fully meet the demand for irrigation equipment, stimulated by State support (subsidies) of agricultural producers within the framework of the Land Reclamation Program.

\section{Conclusions}

Domestic enterprises have the material and technical base, equipment, and the necessary set of design, technical and technological documentation for serial production, and, to a sufficient extent, copyright for operations on the territory of the Russian Federation. The development of domestic production and the creation of competitive irrigation equipment is associated with the implementation of a full cycle of scientific research and experimental design developments, solving the issues of the widespread introduction of domestic irrigation equipment.

To solve the problems of creating and developing domestic production, comprehensive measures of State support are needed, which should consist of the implementation of areas related to the development of reclamation, scientific and technical infrastructure, and strengthening the material and technical base of scientific institutions, as well as stimulating 
domestic production and creating a favorable competitive environment for domestic producers of irrigation equipment.

A planned load of production capacities is required for the development of domestic production, as well as State support within the framework of the Land Reclamation Program, by supplementing the Subsidy Procedure with the provision that "a subsidy to agricultural producers is provided when reclaimed land is put into operation, only in the case of using irrigation machinery and equipment of domestic production. State subsidies to agricultural producers for the use of foreign irrigation machinery and equipment are allocated only in the absence of Russian analogs."

Consider and resolve the issue of establishing duties on irrigation machinery and equipment imported into the Russian Federation, including sprinklers, as has already been done in other industries of the Russian Federation. Provide for the clause "foreign irrigation machinery and equipment are not subject to duty in the absence of Russian analogs."

On the other hand, it is necessary to toughen the responsibility of agricultural producers for the quality and technical level of design solutions and construction of on-farm irrigation systems, to oblige to report on the efficiency indicators of the operation of reclaimed lands and to restore the form of statistical reporting on the production of products on reclaimed lands and the technical condition of on-farm irrigation systems.

The implementation of a set of measures to support domestic manufacturers of sprinkler equipment will allow the implementation of the decisions of the Government of the Russian Federation on import substitution, ensure the observance of the social and economic interests of Russia and the solution of the tasks of the Doctrine of Food Security of the country, as well as will certainly lead to the development of production, the expansion of the tax base, the creation of thousands of new jobs, building new cooperative ties between Russian machine-building enterprises, which means increasing the efficiency of domestic machinebuilding production and replenishing the budgets of the Russian Federation at all levels with tax payments of Russian manufacturers.

\section{References}

1. The State Program for the Development of Agriculture, Regulation of Raw Materials and Food Markets, approved by the Decree of the Government of the Russian Federation No. 717 of June 14, 2021, as amended by the Resolution of the Government of the Russian Federation No. 415 of March 18, 2021. Official portal of the Ministry of Agriculture of the Russian Federation. (2021). https://mcx.ru

2. Report on the implementation of stage I (2014-2017) of the Federal Target Program "Development of land reclamation of agricultural lands in Russia for 2014-2020" (Moscow: Federal State Budgetary Scientific Institution "Rosinformagrotech", 2018)

3. G.V. Olgarenko, S.S. Turapin, Melior. and aq. households 2, 35 (2016)

4. 4. G.V. Olgarenko, V.I. Gorodnichev, S.S. Turapin et al., Resource-saving energyefficient environmentally friendly technologies and technical means of irrigation: Handbook. (M: FGBNU "Rosinformagrotech"), 503 p. (2015)

5. Analytical studies of the prospects for the development of irrigation technology in Russia: Information and analytical edition, 128 p. (M: Kolomna .: IP Lavrenov A.V., 2020)

6. Information portal of FGBNU VNII "Raduga". RainbowInform (2021). https://informraduga.ru

7. G.V. Olgarenko, S.S. Turapin, SGEM. 19(3-1), 443 (2019) 
8. G.V. Olgarenko, V.I. Gorodnichev, S.S. Turapin et al., Methodological recommendations for monitoring indicators and proposals for improving the technical level of irrigation and drainage systems (Kolomna: IP Vorobiev O.M., 2015)

9. G.V. Olgarenko, A.A. Ugryumova, Development of irrigated agriculture in the regions of Russia: trends and prospects: monograph, 250 p. (Moscow: RUSAYNS, 2019)

10. G.V. Olgarenko, Melior. and aq. households 2, 5 (2011)

11. Reclamation complex of the Russian Federation, 304 p. (Moscow: FGBNU "Rosinformagrotech", 2020) 